\title{
SOEP
}

SOEPpapers

on Multidisciplinary Panel Data Research

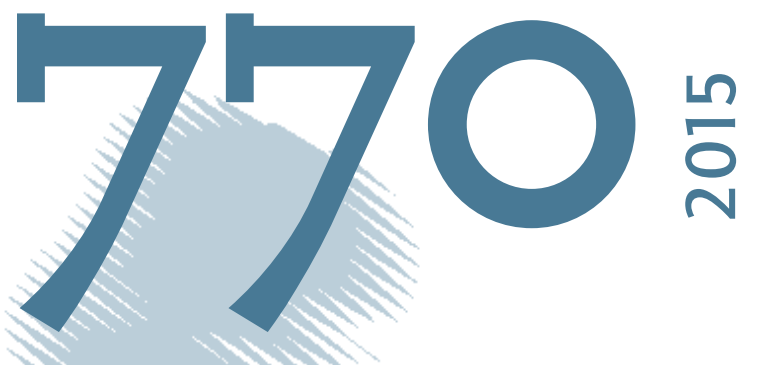

\section{Life-cycle Incidence of Family Policy Measures in Germany: Evidence from a Dynamic Microsimulation Model}


This series presents research findings based either directly on data from the German SocioEconomic Panel study (SOEP) or using SOEP data as part of an internationally comparable data set (e.g. CNEF, ECHP, LIS, LWS, CHER/PACO). SOEP is a truly multidisciplinary household panel study covering a wide range of social and behavioral sciences: economics, sociology, psychology, survey methodology, econometrics and applied statistics, educational science, political science, public health, behavioral genetics, demography, geography, and sport science.

The decision to publish a submission in SOEPpapers is made by a board of editors chosen by the DIW Berlin to represent the wide range of disciplines covered by SOEP. There is no external referee process and papers are either accepted or rejected without revision. Papers appear in this series as works in progress and may also appear elsewhere. They often represent preliminary studies and are circulated to encourage discussion. Citation of such a paper should account for its provisional character. A revised version may be requested from the author directly.

Any opinions expressed in this series are those of the author(s) and not those of DIW Berlin. Research disseminated by DIW Berlin may include views on public policy issues, but the institute itself takes no institutional policy positions.

The SOEPpapers are available at http://www.diw.de/soeppapers

\section{Editors:}

Jan Goebel (Spatial Economics)

Martin Kroh (Political Science, Survey Methodology)

Carsten Schröder (Public Economics)

Jürgen Schupp (Sociology)

Conchita D'Ambrosio (Public Economics)

Denis Gerstorf (Psychology, DIW Research Director)

Elke Holst (Gender Studies, DIW Research Director)

Frauke Kreuter (Survey Methodology, DIW Research Fellow)

Frieder R. Lang (Psychology, DIW Research Fellow)

Jörg-Peter Schräpler (Survey Methodology, DIW Research Fellow)

Thomas Siedler (Empirical Economics)

C. Katharina Spieß (Education and Family Economics)

Gert G. Wagner (Social Sciences)

ISSN: 1864-6689 (online)

German Socio-Economic Panel Study (SOEP)

DIW Berlin

Mohrenstrasse 58

10117 Berlin, Germany

Contact: Uta Rahmann | soeppapers@diw.de 


\title{
Life-cycle Incidence of Family Policy Measures in Germany: Evidence from a Dynamic Microsimulation Model $^{*}$
}

\author{
Holger BONIN \\ (ZEW Mannheim, University of Kassel and IZA Bonn) \\ Karsten REUSS \\ (VDI Technologiezentrum, Düsseldorf) \\ Holger STICHNOTH \\ (ZEW Mannheim)
}

June 29, 2015

\begin{abstract}
This paper quantifies the life-cycle incidence of key family policy measures in Germany. The analysis is based on a novel dynamic microsimulation model that combines simulated family life-cycles for a base population from the 2009 wave of the German Socio-Economic Panel (SOEP) with a comprehensive tax-benefit model. The results indicate that households in Germany benefit considerably from family- and marriage-related transfers, yet also reveal substantial variation behind the population average. Moreover, it is shown that some measures, such as income tax splitting, may make individuals in fact worse off, in financial terms, over the long course, as a result of negative labour supply incentives which are reinforced through detrimental effects on human capital accumulation.
\end{abstract}

JEL Classification: C53, C54, J12, J13, J22

Keywords: Dynamic Microsimulation, Family Policy, Germany

* Work on this paper began as part of a project financed by the German Federal Ministry of Finance (BMF) and the Federal Ministry of Family Affairs, Senior Citizens, Women and Youth (BMFSFJ), cf. Bonin et al. (2013). The views expressed in the report and in the present paper are those of the authors and not necessarily those of the ZEW or the two ministries. The paper employs data of the Socio-Economic Panel (SOEP), version 27, SOEP, 2011, doi:10.5684/soep.v27. Corresponding author: Holger Bonin, ZEW Centre for European Economic Research, P.O. Box 103443, 68034 Mannheim, Germany, bonin@zew.de. 


\section{Introduction}

Studies of earnings inequality increasingly compare outcomes not in a cross-section, but over the life-cycle (e.g., Bowlus and Robin 2012). Adopting such a life-cycle perspective is also important for assessing the effects of tax-benefit systems (e.g., Nelissen 1998). However, the analysis is made difficult by the fact that available data sets rarely span the entire lifecycle of individuals or households. Researchers have dealt with this challenge in two ways: one possibility is to adopt a "slicing" approach which stiches agents observed at different ages together, with the extreme case of converting a single cross-section into a synthetic cohort, as in the computation of total fertility rates. The second possibility is to rely on simulation methods in which observed initial conditions and estimated transition probabilities are combined to generate artificial life-cycles (Orcutt 1957). This has the advantage (cf. Levell and Shaw 2015 for a comparison of the two approaches) of producing individual-level transitions and of being more amenable to counterfactual analysis.

The first contribution of this paper is to develop such a dynamic microsimulation model (ZEWDMM) for Germany. The model simulates adult life-cycles for a base population drawn from the 2009 wave of the German Socio-Economic Panel (SOEP). Transition probabilities are estimated based on SOEP panel data for the years 1995 to 2010. The second contribution is an application of this new model to the study of family-related policies in Germany. In order to do so, we combine the synthetic life-cycles with a tax-benefit simulation model. Existing studies of the life-cycle incidence of family policy measures in Germany are few and have either analysed the incidence of family policy measures for typical life-cycles (e.g., Werding and Hofmann 2006), or have approximated the life-cycle using cross-sectional information (Bonin and Spieß 2007; Bonin, Horstschräer and Spieß 2008).

Three sets of results emerge from our analysis. First, we show that households in Germany receive considerable family- and marriage-related transfers. The population average over the adult life-cycle (excluding the pension system) amounts to 133 thousand euros. Second, we document that there is substantial variation in this amount, with respect to the number of children, or the number of years spent as a single parent. Individuals who experience long spells as single parent tend to receive less financial support compared to parents who always live in a couple, or are single parents for at most five years over the life-cycle, even controlling for the number of children. Finally, we use the model to quantify the long-run consequences of the labour supply incentives set by the different family policy measures. In static, 
cross-sectional microsimulation studies (e.g. Bonin, Stichnoth, and Schnabel 2014), two of the measures in particular - income tax splitting and the free coinsurance of spouses in the public health and long-term care insurance system - have been found to considerably reduce the labour supply of secondary earners. We show that over the life-cycle, the reduction in labour supply induced by these measures might even leave households worse off financially.

The remainder of the paper is structured as follows. Sections 2 and 3 describe the new dynamic microsimulation model for Germany (ZEWDMM), and the tax-benefit simulation model, respectively. Section 4 reports the key results of the analysis, while Section 5 concludes.

\section{The Dynamic Microsimulation Model ZEWDMM}

\subsection{Overview}

This section describes the ZEW Dynamic Microsimulation Model (ZEWDMM). The basic idea of dynamic microsimulation is to simulate the behaviour of a base population of micro-units (e.g., individuals or households) over time. The simulated population can then be used to analyse various policies. While the present application focuses on family policies, ZEWDMM is more general and can be put to other uses in future research as well.

ZEWDMM simulates life cycles for a base population from the 2009 wave of the German Socio-Economic Panel (SOEP). While the model tracks the entire cross-section of 2009, making it a "population model" according to the classification in a recent survey by Li and O’Donoghue (2013). In this article, we will focus on the cohort of households with at least one individual aged 25 to 29 in 2009. Life trajectories are simulated for these households until all household members reach age 65. The model is “open” in the sense that new spouses are generated exogenously based on observed marriage patterns, as opposed to a "closed” model in which spouses would be selected from within the base population. The model is set in discrete time, with each period corresponding to one year. The state variables in the model are age, gender, education, marital status, number and age of children in the household, work experience, firm tenure, and being a resident of either East or West Germany. Earnings and disposable incomes are simulated based on these state variables. Between two periods of the life cycle, we allow for "dynamic ageing” in the sense that variables are updated by applying laws of motion that have been estimated using SOEP panel data for the years 1995 to 2010. 
In the following, we will present the different components of the model in greater detail. We will also show results from a baseline simulation that constitutes the point of departure for the policy analysis in the next section.

\subsection{Base population}

Our base population is drawn from the SOEP wave of 2009. The SOEP is a longitudinal survey of private households, with a rich set of information on personal and household characteristics. ${ }^{1}$ We keep only those agents for whom all information required for simulating taxes and transfers (cf. Section 3) is available.

ZEWDMM is able to simulate trajectories for the entire cross-section. However, for the present purpose, we focus on households in which at least one individual is between 25 and 29 years old in 2009. The members of this group are (1) old enough so that most individuals have completed their education and at the same time (2) young enough so that we can follow them over the major part of their (family) life-cycles. ${ }^{2}$

Summary statistics for this cohort, which constitutes the base population for our simulation, are shown in Table 3. As expected, men in the base population tend to be slightly older than women. About a quarter of all households reside in East Germany, and 27\% of all households are married couples. In $29 \%$ of households we observe a child younger than age 18. While there are hardly any gender differences as regards education, women are much more likely not to be employed, or if they are employed, to be working part-time. This gender differential is also reflected in gender differences with respect to work experience and tenure. Men earn on average 14.2 euros per hours, while women earn 11.1 euros. Thus, the raw gender pay gap is about $22 \%$, in line with common results for Germany.

\subsection{Dynamic ageing}

The model is set in discrete time, with each period corresponding to a year. Each (adult) person in each year is fully characterized by the following state variables: age, gender, education, marital status, number and age of children in the household, work experience, firm ten-

\footnotetext{
${ }^{1}$ See Wagner et al. (2007) for a detailed description.

${ }^{2}$ Results for all cohorts are reported in Bonin et al. (2013).
} 
ure, residence in East or West Germany. Earnings and disposable incomes are simulated based on these state variables.

Between periods $t$ and $t+1$, all individuals age by one year. Any other state variable may also change. ${ }^{3}$ The state variables follow laws of motion that will be described below. By basing our simulated life trajectories on these laws of motion, our model follows a dynamic ageing approach, as opposed to the static ageing process described in Immervoll et al. (2005). Static ageing means that the individual and household characteristics of the base population are left intact, with only the weights being adjusted. For instance, an ageing population would be simulated by increasing the weight of old individuals in the base population, while at the same time decreasing the weight of young people. This method has the advantage of simplicity, but could not be used for the purposes of our article, as the life-cycle take-up of family policy measures hinges on life histories, including the change in take-up around events such as marriage, child birth, or divorce. With a static ageing approach, no individual or household would ever experience these events, as the dynamics are introduced exclusively through reweighting.

The simulation ends when individuals reach age 65. For couples, the simulation continues until the younger spouse reaches this upper age limit.

The laws of motion are estimated based on data from the SOEP, so the base population and the transition probabilities come from the same dataset. While the base population is from a single cross-section, the estimation of the laws of motion uses information covering a longer time span (1995-2010).

Based on the estimated laws of motion, we simulate life trajectories for each individual by drawing from the probability distributions. All results are based on averages over 50 runs. ZEWDMM is a recursive model. This means that in the simulation, the different state variables are updated in sequential fashion. Child-related transitions (fertility, children leaving the parental household) are considered first. Marriages and employment-related changed are sim-

\footnotetext{
${ }^{3}$ We simplify by taking the highest educational degree as given - considering our minimum starting age of 25 years, this is arguably a reasonable approximation. Of course, people will still accumulate human capital through learning on the job. (We do not consider formal training, however.) We also simplify by abstracting from mortality. As our simulation stops at age 65, our conclusions should not be greatly affected by this. Finally, we keep the place of residence (East or West Germany) fixed.
} 
ulated next, and divorces are predicted last, because they lead to formation of new households. A recursive structure of this kind is a standard feature in dynamic microsimulation models, due to the fact that the alternative of estimating and simulating all state transitions jointly is not feasible given the size of available datasets. Instead of estimating one large transition matrix with many sparsely populated or even empty cells, we therefore follow the literature and estimate the different laws of motion separately, under the admittedly quite simplifying assumption of independent error terms.

\section{Fertility}

The law of motion for fertility is estimated based on a probit model. The probability of giving birth in a given year depends on age, education, marital status, employment status, and the number of existing children. We also include an indicator variable for the years after 2005, in which the system of social assistance and unemployment assistance underwent major changes. While this indicator is particularly important for the employment transitions, we include it in the other models as well, in order to allow for the possibility of a wider ranging structural break.

The parameter estimates for the fertility model are documented in Table 4. The estimation confirms well-known patterns, such as a negative association between education and the number of births. Note that the parameters of the model are not meant to be given a causal interpretation. We are well aware of the debate about the causal relationship between education and fertility (e.g., McCrary and Rogers 2011, Hazan and Zoabi, forthcoming), yet our goal is merely to estimate conditional transition probabilities. In this respect, the associations with two of the other state variables are of particular importance: we find that married women and women who are currently not employed have a higher birth probability.

\section{Household composition}

The probability of marriage is again estimated using a probit model. We include the following covariates: age, education, the number of children in the household, as well as indicator variables for (unmarried) cohabitation and for the years after 2005. Parameter estimates are shown in Table 5. In the simulation, a person who marries is assigned a partner based on the marriage patterns observed in the SOEP 1995-2010. New spouses are generated exogenously, as opposed to a closed model in which spouses would be selected from within the base population. 
Divorce probabilities come from a probit model which conditions on the age of the husband, the age difference between husband and wife, the number of children in the household, and on indicator variables for the labour force participation of each spouse. Among other things, we find that a larger age difference is associated with a higher divorce risk (cf. Table 6). The divorce risk is lower, if the husband is employed. Female labour force participation is associated with a higher divorce risk, although the relationship is not statistically significant at conventional levels.

In the simulations, we assume that after a divorce children remain with their mother, while fathers start a new household. The spin-off household remains part of the simulation. By assumption, direct remarriage is ruled out, so divorced individuals spend at least one period as singles.

Finally, household composition is affected by the presence of children. The share of children still living in their parents' household is estimated based on data from the SOEP 1995-2010.

\section{Employment status}

Our model distinguishes four employment states: not employed, working between zero and 15 hours (typically in so-called Minijobs that are exempt from income taxation and employee's social security contributions), working part-time between 15 and 35 hours, and working full-time, i.e., more than 35 hours. ${ }^{4}$

The factors driving the transitions between these states are estimated using multinomial logit models. We estimate eight such models, depending on the sex of the person and her/his current employment state. All models condition on age, education, as well as indicator variables for living in East Germany and for the years after 2005. We also include dummy variables for births that occurred in the past year. For women, we additionally include births in t-2, $\mathrm{t}-3$, and $\mathrm{t}-4$ among the predictor variables. All these birth variables are interacted with an indicator for the years after 2007, when a major reform of the system of parental leave benefits affected employment behaviour for both women and men.

${ }^{4}$ For the simulation of gross earnings and disposable incomes, these employment states are assumed to correspond to $0,10,20$, and 40 hours per week, respectively. 
In the multinomial logit models with individual-specific covariates, the coefficients are specific to the alternatives, with one of the four alternatives serving as the reference category. We thus obtain 24 sets of estimation results (we estimate separately for men and women and have in each case three sets of parameters for each of the four possibilities for the initial employment state). ${ }^{5}$

\section{Wages}

Wages are predicted using OLS regressions, with the logarithm of the gross hourly wage as dependent variable. Estimation is carried out separately for men and women. Wages are predicted based on education, experience, and tenure. ${ }^{6}$ Table 7 documents the estimated coefficients.

We assume that the wage equation remains unchanged even if the number of people in employment (or their weekly working hours) changes. Abstracting from general equilibrium considerations is standard in the dynamic microsimulation literature. Models that link the household model with a labour demand model, e.g., through a computable general equilibrium model, are still rare (see Colombo 2008 for a discussion). As we consider only a particular age group, abstracting from general equilibrium effects is arguably less problematic than in a model that aims at a representation of the entire population.

\section{Institutions and Family Policy Measures}

In order to evaluate the take-up of family policy measures over the life-cycle, the dynamic microsimulation model ZEWDMM is linked with a static tax-benefit simulator. For each household in each year, the simulator translates gross earnings (in a couple, the sum of

${ }^{5}$ The results are not shown in the paper for the sake of brevity, but are available from the authors upon request.

${ }^{6}$ In the simulation, work experience is increased by 1 for each year in full-time work and by 0.5 for parttime employment. Firm tenure increases by 1 for each year spent in employment. When a person changes from full-time employment into non-employment, tenure is reset to zero. The same is assumed in cases where individuals transit from full-time employment into a job that is exempt from social security contributions and taxes (Minijob) or vice versa - the idea is that such drastic changes of work arrangements are unlikely to take place within the same firm. In contrast, going from full-time to standard part-time work does not reset the tenure counter. 
gross earnings of both spouses) into disposable income at the household level. The yearly results are then summed up over the life-cycle.

As noted above, our model abstracts from general equilibrium considerations. In the context of tax-benefit simulation, this means that the simulation does not impose a government budget constraint. Changes in benefit spending are therefore not offset via tax adjustments, nor do higher or low tax revenues trigger changes in benefit generosity. This assumption is a normal feature in dynamic microsimulation, especially in models focusing on a single cohort rather than the entire population.

In our model, the wedge between gross earnings and disposable income arises because of income taxes, social security contributions, housing benefits, and social assistance. Among other things, these will depend on marital status and the number of children, as well as their age. The simulation is carried out for the German tax-benefit rules of the year 2010 (the first year for which our base population from 2009 needs to be simulated). We therefore assess the impact of family policy measures under the assumption that these rules will stay in place over the entire life-cycles of the population under study. While in reality there will of course be adjustments, predicting these changes is beyond the realm of this paper. Moreover, these changes will not affect the basic conclusions as long as they merely consist in inflation adjustments. Using the 2010 values for both wages and policy parameters is equivalent to a situation in which both grow at the same nominal rate and are then deflated back to this base year.

The starting point of the simulation model is gross labour earnings. These depend on the hourly wages and the employment state. Monthly gross earnings are obtained by multiplying gross hourly wages by the number of hours worked per week and by the average number of weeks per month. Minijobs are assumed to always pay 400 euros per month. Social security contributions are simulated based on these gross earnings.

Taxable income is obtained from gross earnings after deducting certain standard allowances. Income tax is computed by plugging taxable income into a tax function. Married couples in Germany can file a joint income tax declaration and benefit from income tax splitting, i.e., the tax function is applied to the mean of both spouses' taxable income, and the tax payment is then doubled. As the income tax scheme is progressive, this tends to make households better off than a system of individual taxation unless both partners have exactly the same taxable income. By making both spouses' marginal tax rate equal, income tax splitting creates 
work disincentives for the secondary earner, in most cases the woman. The disincentives are particularly strong at the Minijob threshold, below which earnings are exempt from income tax and employee's social security contributions.

Households may be entitled to a number of benefits and transfer payments. These usually depend on household income, on the number and age of the children in the household, and on the labour market states. For instance, certain transfers such as parental leave benefits are conditional on working less than 30 hours per week, ruling out full-time employment. Social assistance ( $A L G I I)$ payments depend on the level of earnings, the number of persons in the household and on the cost of rent and heating. ${ }^{7}$ The latter are observed in the base period of 2009. In later years (in which the household composition may change), we impute these costs based on a prediction model estimated for the 2009 cross-section. The costs of rent and heating also enter the simulation of housing benefits (Wohngeld).

A transfer that is of special interest in the context of family policy is parental leave benefits. In 2007, Germany reformed its system of parental leave benefits. The previous meanstested child-rearing benefit (Erziehungsgeld) was replaced by Elterngeld, which depends on (individual) earnings in the year before childbirth. In most cases, the replacement rate is 67\%. The benefit is capped at 1800 euros per month, but nevertheless represents a substantial transfer, especially compared to the previous child-rearing benefit. In order to obtain the benefit, at least one of the parents has to reduce working hours below a threshold of 30 hours per week. The benefit is paid for a maximum of twelve months.

Child benefits and child tax allowance can be received for up to 25 years (and even longer in a few exceptional cases neglected here, such as when the child is handicapped). In 2010, child benefits amounted to 184 euros per month for the first two children, 190 euros for the third child and 215 euros for additional children. Alternatively, households could deduct a tax allowance of 7008 euros per child from their annual taxable income, which is advantageous for households with a high income.

Another factor of importance when modelling fertility and employment decisions is the cost and availability of childcare. Public childcare has long been in short supply in Germany, in particular for children aged younger than 3 . We estimate the probability that a child of a

\footnotetext{
${ }^{7}$ We do not allow for payments from the unemployment insurance (ALG I) as tracking the entitlements is rather cumbersome. We therefore assume that the unemployed immediately fall under the ALG II regime.
} 
given age attends a day care centre (and the expected parental fees in this case) using data from the 2002, 2005, and 2007 waves of the SOEP, which provide detailed information on childcare use and costs.

We assume that all individual retire at age 65. Early retirement (in the sense of an irreversible decision, i.e. an absorbing state) is not formally modelled, but the employment transitions do capture the observed reduction of labour supply among older workers. Pension entitlements are simulated based on the 2010 rules of the German pension insurance. Entitlements can be accumulated through social security contributions while working, and in addition through special allowance periods associated with childcare.

\section{$4 \quad$ Results}

The ZEW Dynamic Microsimulation Model (ZEWDMM) provides us with synthetic life-cycles for a base population of households with at least one individual aged 25 to 29 in 2009. We feed these life cycles into a tax-benefit simulation model that captures the key features of the German tax-benefit system of 2010. We then use the simulation to analyse the incidence of German family policy measures over the entire (adult) life-cycle. Such an analysis is not possible based on available data sets that - even in the best of cases, i.e. long-run panel data - cover only some parts of this life-cycle for each individual.

Table 1 shows the value of the family policy measures (in 2010 euros) that different household types will receive over their (simulated) life-cycles. The average over all households is a substantial 133 thousand euros. About half of this financial support is in the form of child benefits or, in a few cases, child tax allowance. According to the simulations, the tax advantage arising from income tax splitting amounts to 31 thousand euros over the life-cycle for a typical household.

Although concentrated on just a few years, subsidised childcare represents a sizeable 21 thousand euros. This is due to the fact that slot in public childcare is heavily subsidised, with parental fees covering only about $14 \%$ of actual costs (Schilling 2008).

Monetary transfers as defined here comprise both parental leave benefits and classical transfers that are targeted to low-income households; a typical household will receive about 16 thousand euros in transfers over the life-cycle. The value of the co-insurance of spouses in the public health and long-term care insurance is about 2 thousand euros. Note, however, that this is a net figure that takes into account the budget constraint of the two insurance systems. 
To arrive at this figure, we simulate a benchmark situation in which married couples would lose the possibility of free coinsurance, but in which everyone enjoys a lower social security contribution rate. ${ }^{8}$

Table 1: Value of family policy measures over the life-cycle

\begin{tabular}{|c|c|c|c|c|c|c|c|}
\hline $\begin{array}{l}\text { Children } \\
\text { over life- } \\
\text { cycle }\end{array}$ & $\begin{array}{c}\text { Years as } \\
\text { single parent }\end{array}$ & Total & $\begin{array}{l}\text { Child bene- } \\
\text { fits/child tax } \\
\text { allowance }\end{array}$ & $\begin{array}{c}\text { Monetary } \\
\text { transfers }\end{array}$ & $\begin{array}{l}\text { Tax advan- } \\
\text { tages }\end{array}$ & $\begin{array}{c}\text { Social securi- } \\
\text { ty }\end{array}$ & $\begin{array}{c}\text { Subsidised } \\
\text { childcare }\end{array}$ \\
\hline 0 & None & 14 & 0 & 0 & 20 & -6 & 0 \\
\hline \multirow[t]{3}{*}{1} & None & 118 & 53 & 13 & 30 & 3 & 18 \\
\hline & $<=5$ Years & 119 & 53 & 13 & 31 & 3 & 18 \\
\hline & $>5$ Years & 108 & 54 & 15 & 21 & -1 & 18 \\
\hline \multirow[t]{3}{*}{2} & None & 199 & 97 & 23 & 38 & 8 & 32 \\
\hline & $<=5$ Years & 201 & 100 & 24 & 37 & 8 & 32 \\
\hline & $>5$ Years & 191 & 102 & 27 & 26 & 3 & 33 \\
\hline \multirow[t]{3}{*}{$>=3$} & None & 293 & 151 & 39 & 42 & 13 & 48 \\
\hline & $<=5$ Years & 298 & 155 & 39 & 42 & 12 & 50 \\
\hline & $>5$ Years & 284 & 156 & 43 & 29 & 6 & 49 \\
\hline \multicolumn{2}{|c|}{ Average } & 133 & 64 & 16 & 31 & 2 & 21 \\
\hline
\end{tabular}

Source: Simulations with the ZEW Dynamic Microsimulation Model (ZEWDMM). Initial conditions from SOEP 2009, households with at least one individual aged 25-29. Transition probabilities estimated based on SOEP 1995-2010. All numbers in 2010 euros. The rules for the tax-benefit simulation are for the year 2010.

The simulations show that there is substantial variation both in the total value and the structure of these family policy measures across family types (cf. Fehler! Ungültiger Eigenverweis auf Textmarke. in the Appendix for their simulated distribution). The roughly 20\% of households in the cohort who are predicted to remain childless over their entire life-course will receive only about 14 thousand euros on average, whereas the $20 \%$ of households who have three or more children receive financial support of almost 300 thousand euros. Roughly speaking, in Germany, each additional child represents an extra 90-100 thousand euros of net government transfers over the life.

\footnotetext{
${ }^{8}$ Formerly free coinsurance is replaced by a monthly payment of 132.15 euros. In exchange, the contribu-
} tion rate decreases from 8.875 to 7.78 percent. The calculations behind these numbers are explained in Bonin, Stichnoth and Schnabel (2014). 
Interestingly, individuals who experience long spells as a single parent tend to receive somewhat less financial support than parents who always live in a couple or are single parents for at most five years over the life-cycle, even controlling for the number of children. This result is driven by the fact that single parents cannot benefit from income tax splitting or free co-insurance of spouses. At the same time, measures that are targeted towards them do not effectively reach them, such as a specific income tax allowance for single parents irrelevant for low or no earners, or pay for only a limited number of years, such as the monetary support from the state in cases when former partners default on the child alimony payments (Unterhaltsvorschuss).

Figure 1: Average yearly value of family policy measures, by number of children

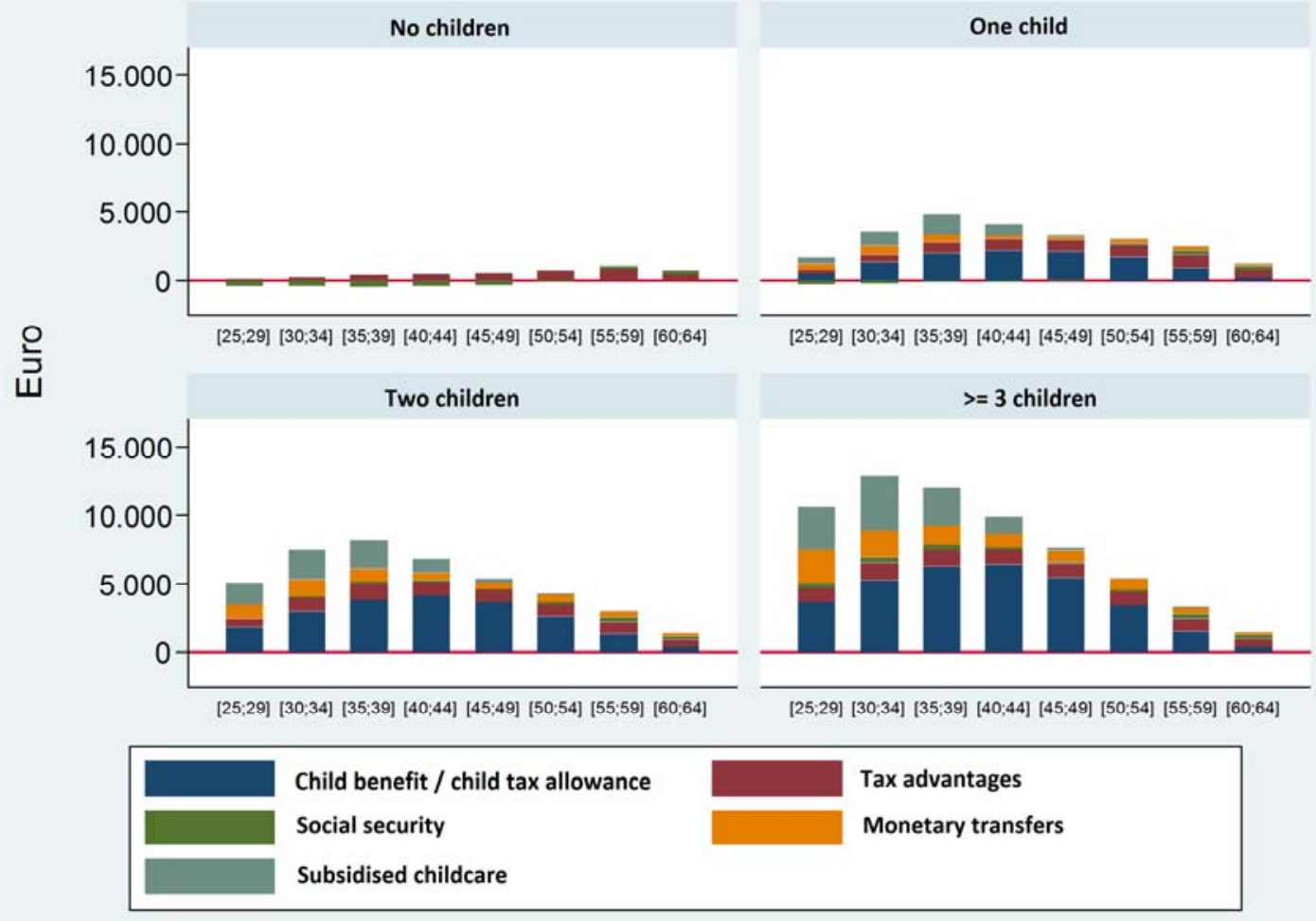

Source: Simulations with the ZEW Dynamic Microsimulation Model (ZEWDMM). Initial conditions from SOEP 2009, households with at least one individual aged 25-29. Transition probabilities estimated based on SOEP 1995-2010. All numbers in 2010 euros. The rules for the tax-benefit simulation are for the year 2010. 
So far, we have reported total amounts over the life-cycle. The model can also be used to analyse how the level and structure of family policy measures varies by age of the youngest adult household member. As Figure 1 shows, the level of financial support corresponds closely to the presence of children in the household. The support reaches its maximum in the years following childbirth, when most families benefit first from parental leave benefits and then from subsidised childcare. The total value of financial support to families can reach substantial amounts in those years. When households who have (or will have) three or more children over the life-cycle are in their early 30s, they receive more than 10 thousand euros per year on average. For households who remain childless, by contrast, the financial advantages are much less variable over the life-cycle. For them, the yearly value tends to increase slightly with age, as - other things equal - the splitting advantage increases with taxable income.

The dynamic microsimulation model also allows studying directly how the incidence of family policies changes around key life events such as marriage, divorce, or childbirth. Such an analysis is possible as the model generates transitions at the household level, unlike studies which construct synthetic cohorts solely based on cross-sectional information (e.g., Bonin and Spieß 2007; Bonin, Horstschräer, and Spieß 2008). Yet for this type of analysis, the new model does not offer any principal advantage here over a direct analysis of the underlying panel data. The results are therefore not shown here, but are documented in Bonin et al. (2013).

By contrast, a key advantage of our dynamic microsimulation approach is the possibility of running counterfactual analyses. In particular, we can replace the estimated transition probabilities by any other set of values. For instance, we could predict fertility behaviour based on a hypothetical situation in which, say, birth probabilities were generally higher or followed a different age pattern or education gradient.

In the present paper, however, we focus on a different application and take into account that several of the family policy measures - most notably income tax splitting and the coinsurance of spouses - have been shown to affect labour supply behaviour. So far, this has been established mostly using static microsimulation models (e.g., Bonin, Stichnoth, and Schnabel 2014). Given the negative effect of these measures on the labour supply of secondary earners (typically the wife), the question arises whether in the long run couples may actually be made worse off financially through these measures. While an answer to this question should ideally be based on a model in which households optimize over the life-cycle, the pre- 
sent dynamic microsimulation model already highlights and quantifies the trade-off between short-run financial advantages and long-run costs arising from a slower accumulation of human capital.

In order to analyse the long-run effects of income tax splitting and other family policy measures that result from a change in labour supply behaviour, we plug short-run labour supply effects drawn from Bonin, Stichnoth, and Schnabel (2014) into the dynamic microsimulation model. In this experiment, all other transition equations are assumed to remain the same.

To be specific, for income tax splitting, the short-run model predicts that wives' labour force participation is lower by 2.27 percentage points, if individual taxation serves as benchmark. Conditional on working, wives tend to reduce their weekly labour supply by 0.32 hours. Labour supply of husbands, on he other hand, is more or less unchanged at the extensive margin, while income tax splitting induces them to work slightly longer per week. Over the lifecycle, these changes in labour supply accumulate and are further reinforced as less human capital means lower wage offers, which in turn tends to reduce labour supply incentives. All in all, the simulation predicts that the reduction in labour supply resulting from income tax splitting lowers disposable income by about 30 thousand euros.

Another marriage related implicit transfer, which substantially reduces labour supply and thus earnings of second earners, is free coinsurance of non-working or marginally employed spouses in statutory public health care insurance. The simulated loss in life cycle associated with this measure is about 21 thousand euros per household.

Germany's rather generous parental leave policy also sets incentives for people to work less, if only in the first year after birth. This translates into a reduction in disposable income through earnings by on average 5.5 thousand euros. Note, however, that the benchmark of this simulation is a situation without any parental leave benefits at all, not a comparison with the pre-2007 system of Erziehungsgeld (which affected fewer people but set incentives for a longer career break of 24 months). Social assistance (or more precisely, its child related component) is simulated to reduce earnings per household by about 4.2 thousand euros over the life-course. This is an average over all households, most of whom will never receive social assistance. The remaining family policy measures studied have even smaller second round earnings effects stemming from labour supply (dis-)incentives.

It is important to note, however, that the income effects associated with changing labour supply trajectories are dwarfed by the direct income effects, for almost all measures (Table 2). 
The same holds true for the interactions within the tax-benefit system, e.g. the fact that child benefits are taken into account in the calculation of social assistance, which means that, say, the hypothetical abolition of child benefits would not reduce disposable life-cycle income by exactly the same amount.

Table 2: Total value of family and marriage related policy measures over the life-cycle

\begin{tabular}{|c|c|c|c|}
\hline & (1) & (2) & (3) \\
\hline & Direct effect & $\begin{array}{l}\text { Taking into account } \\
\text { interactions within the } \\
\text { tax-benefit system }\end{array}$ & $\begin{array}{l}\text { Taking into account inter- } \\
\text { actions and the change in } \\
\text { earnings induced by a } \\
\text { change in labour supply }\end{array}$ \\
\hline Child benefits/child tax allowance & 63680 & 43422 & 42231 \\
\hline Subsidised childcare & 20498 & 15080 & 13132 \\
\hline Housing benefits (child-related) & 1571 & 1219 & 1074 \\
\hline Tax allowance for single parents & 683 & 521 & 496 \\
\hline Advance payment of child alimony & 820 & 243 & 152 \\
\hline $\begin{array}{l}\text { Reduced contribution rate, long-term } \\
\text { care insurance }\end{array}$ & -465 & -315 & 151 \\
\hline Tax deductability of childcare expenses & 161 & 157 & 148 \\
\hline Child benefit supplement & 535 & 398 & 125 \\
\hline Social assistance (ALG II, child-related) & 7206 & 3493 & -706 \\
\hline Parental leave benefits & 6179 & 4049 & -1447 \\
\hline Income tax splitting & 30007 & 28287 & -2185 \\
\hline Coinsurance of spouses & 2549 & 4710 & -16270 \\
\hline
\end{tabular}

Source: Simulations with the ZEW Dynamic Microsimulation Model (ZEWDMM). Initial conditions from SOEP 2009, households with at least one individual aged 25-29. Transition probabilities estimated based on SOEP 1995-2010. All numbers in 2010 euros. The rules for the tax-benefit simulation are for the year 2010. Short-run labour supply effects are taken from Bonin, Stichnoth, and Schnabel (2014).

For income tax splitting, however, the total effect on life-cycle disposable income does turn out to be slightly negative, at roughly -2000 euros. The child-related component of social 
assistance and parental leave benefits are also found to lead to small net reductions in disposable income. The precise numbers should of course not be over-interpreted, given that they are based on a model in which labour supply reactions are taken from a short-run, i.e. myopic model.

Finally, the strongly negative total effect for free coinsurance of spouses in the statutory public health insurance is to a large extent due to the fact that the direct effect is defined as the net effect of free coinsurance for married spouses and higher contribution rates for everyone. While both components of the scenario undoubtedly tend to depress labour supply, they dominate the total effect only because of the way in which the direct effect is defined.

\section{Conclusion}

This paper has described a novel dynamic microsimulation model (ZEWDMM) for Germany, and reported on the incidence and effects of the most important family- and marriage-related policies over the adult life-cycle between ages 25/29 to 65 . The results indicate that households in Germany benefit substantially from public transfers to families (or married couples). On average, they will receive an amount of 133 thousand euros over their life course upon retirement. Yet there is substantial variation behind this average, with regard to the number of children as well as the number of years spent as a single parent.

Using the model to quantify the long-run consequences of the labour supply incentives set by the different family policy measures shows that for most instruments, the direct transfer effect on income dominates, even if one accounts for the interactions between various policy measures arising through interactions within the tax and transfer system. Income tax splitting appears as an exception: the associated reduction in (female) labour supply may leave households altogether worse off financially in the long run. This result comes about despite the fact that for given earnings, there is a splitting advantage for almost all married couples. However, this finding should be interpreted with some caution. In our setting, labour supply reactions are not modelled through life-cycle optimization, but by repeatedly plugging in short-run labour supply response estimates into the dynamic microsimulation model. Moreover, the findings do not by necessity imply that households are worse off in utility terms, given that the reduction in labour supply brings a welfare gain via a larger amount of leisure.

Another limitation of our current analysis is the fact that the simulation ends at age 65 and therefore disregards the benefits that children generate, at the individual level, in terms of 
additional pension points. In addition, at the aggregate level, bringing up children affects the level of contribution and replacement rates in the pay-as-you-go (pension) schemes, which are under pressure from demographic ageing. Without quantifying these factors, and without taking into account the private costs of children borne by the parents and several public costs (e.g., schooling) that are not yet part of the current simulations, it is difficult to say whether the substantial family-and marriage-related transfers documented here are in any economic sense "optimal”. Therefore, further elaboration of the dynamic microsimulation model introduced here is in order - yet left to future work. 


\section{References}

Bonin, H.; Pfeiffer, F.; Reuß, K.; Stichnoth, H. (2013): Mikrosimulation ausgewählter ehe- und familienbezogener Leistungen im Lebenszyklus - Gutachten im Auftrag der Prognos AG für das Bundesministerium der Finanzen und das Bundesministerium für Familie, Senioren, Frauen und Jugend, ZEW Mannheim.

Bonin, H.; Spieß, C.K. (2007): Inanspruchnahme familienbezogener Leistungen im Lebensverlauf, Expertise im Auftrag der Prognos AG, Berlin.

Bonin, H.; Horstschräer, J.; Spieß, C.K. (2008): Heterogene Wirkungen ehe- und familienbezogener Leistungen im Lebensverlauf, Mannheim.

Bonin, H.; Stichnoth, H.; Schnabel, R. (2014): Zur Effizienz der ehe- und familienbezogenen Leistungen in Deutschland im Hinblick auf soziale Sicherungs- und Beschäftigungsziele, Vierteljahrshefte zur Wirtschaftsforschung 83(1), 29-48.

Bowlus, A.J.; Robin, J-M. (2012): An international comparison of lifetime inequality: how continental Europe resembles North America, Journal of the European Economic Association, 10, 1236-1262.

Colombo, G. (2008): Linking CGE and Microsimulation Models: A Comparison of Different Approaches, ZEW Centre for European Economic Research Discussion Paper No. 08054, Mannheim.

Hazan, M.; Zoabi, H. (forthcoming): Do highly educated women choose smaller families?, Economic Journal.

Immervoll, H.; Lindström, K.; Mustonen, E.; Riihelä, M.; Viitamäki, H. (2005): Static Data Ageing Techniques: Accounting For Population Changes In Tax Benefit Microsimulation Models, EUROMOD Working Papers EM7/05.

Levell, P.; Shaw, J. (2015): Constructing full adult life-cycles from short panels, IFS Working Paper W15/01, London.

Li, J.; O’Donoghue, C. (2013): A survey of dynamic microsimulation models: uses, model structure and methodology, International Journal of Microsimulation 6(2), 3-55. 
McCrary, J.; Royer, H. (2011): The effect of female education on fertility and infant health: evidence from school entry policies using exact date of birth, American Economic Review 101, 158-195.

Nelissen, J.H.M. (1998): Annual versus lifetime income redistribution by social security, Journal of Public Economics 68, 223-249.

Orcutt, G.H. (1957): A new type of socio-economic system, Review of Economics and Statistics 39, 116-123.

Schilling, M. (2008): Kosten für Kindertageseinrichtungen und Kindertagespflege und ihre Finanzierung, in: Deutsches Jugendinstitut (ed.): Zahlenspiegel 2007. Kindertagesbetreuung im Spiegel der Statistik, München.

Wagner, G.G., Frick, J.R.; Schupp, J. (2007): The German Socio-Economic Panel Study (SOEP): Scope, evolution and enhancements, Schmollers Jahrbuch - Journal of Applied Social Sciences Studies 127(1), 139-169.

Werding, M.; Hofmann, H. (2006): Die fiskalische Bilanz eines Kindes im deutschen Steuer- und Sozialsystem, ifo Schnelldienst 59, München. 


\section{Tables and Figures}

Table 3: Summary statistics for the base population

\begin{tabular}{|c|c|c|}
\hline & Men & Women \\
\hline Age & $30.2(4.5)$ & $27.4(1.7)$ \\
\hline Living in East Germany (dummy) & 0.25 & 0.25 \\
\hline Low education (dummy) & 0.09 & 0.10 \\
\hline Medium education (dummy) & 0.62 & 0.61 \\
\hline High education (dummy) & 0.29 & 0.29 \\
\hline Not employed (dummy) & 0.15 & 0.30 \\
\hline Minijob (dummy) & 0.05 & 0.09 \\
\hline Part-time (dummy) & 0.07 & 0.15 \\
\hline Full-time (dummy) & 0.73 & 0.46 \\
\hline Work experience (years) & $6.6(5.1)$ & $3.6(2.7)$ \\
\hline Firm tenure (years) & $4.1(4.8)$ & $2.3(2.9)$ \\
\hline Hourly wage (2010 euros) & $14.2(7.4)$ & $11.1(6.7)$ \\
\hline Married (dummy) & \multicolumn{2}{|c|}{0.27} \\
\hline Child below 18 in household (dummy) & \multicolumn{2}{|c|}{0.29} \\
\hline If yes, number of children below 18 & \multicolumn{2}{|c|}{$1.6(0.8)$} \\
\hline
\end{tabular}

Source: SOEP 2009. The table reports sample means and, where applicable, sample standard deviations (in parentheses). 
Table 4: Birth probability - parameters from a Probit estimation

\begin{tabular}{|c|c|c|}
\hline & \multicolumn{2}{|c|}{ Dependent variable: birth } \\
\hline 1 child so far (dummy) & 0,012 & $(0,032)$ \\
\hline 2 children so far (dummy) & $-0,563 * * *$ & $(0,040)$ \\
\hline More than 2 children so far (dummy) & $-0,468 * * *$ & $(0,053)$ \\
\hline Verheiratet (dummy) & $0,343 * * *$ & $(0,028)$ \\
\hline Age (years) & $-0,031 * * *$ & $(0,006)$ \\
\hline $\mathrm{Age}^{2}$ & $-0,001 * * *$ & $(0,000)$ \\
\hline Medium education (dummy) & $-6,595 * * *$ & $(0,774)$ \\
\hline High education (dummy) & $-7,787 * * *$ & $(1,037)$ \\
\hline (Medium education)*Age & $0,413^{* * *}$ & $(0,049)$ \\
\hline (High education)*Age & $0,470 * * *$ & $(0,063)$ \\
\hline (Medium education)*Age ${ }^{2}$ & $-0,006 * * *$ & $(0,001)$ \\
\hline (High education)*Alter ${ }^{2}$ & $-0,007 * * *$ & $(0,001)$ \\
\hline Not employed (dummy) & $0,161 * * *$ & $(0,031)$ \\
\hline Minijob (dummy) & 0,044 & $(0,047)$ \\
\hline Part-time (dummy) & 0,030 & $(0,035)$ \\
\hline Year >= 2005 (dummy) & $0,053^{*}$ & $(0,027)$ \\
\hline
\end{tabular}

Source: SOEP 1995-2010. Asymptotic standard errors in parentheses ***/**/*: statistically significant at the 1,5, and $10 \%$ levels. 
Table 5: Marriage probability - parameters from a Probit estimation

\begin{tabular}{|c|c|c|c|c|}
\hline \multirow[b]{3}{*}{ Intercept } & \multicolumn{4}{|c|}{ Dependent variable: marriage } \\
\hline & \multicolumn{2}{|c|}{ Men } & \multicolumn{2}{|c|}{ Women } \\
\hline & $-23,339 * * *$ & $(3,730)$ & $-19,364 * * *$ & $(3,452)$ \\
\hline Age (years) & $2,0413^{* * *}$ & $(0,369)$ & $1,785^{* * *}$ & $(0,346)$ \\
\hline $\mathrm{Age}^{2}$ & $-0,069 * * *$ & $(0,013)$ & $-0,064 * * *$ & $(0,013)$ \\
\hline $\mathrm{Age}^{3}$ & $0,001 * * *$ & $(0,000)$ & $0,001 * * *$ & $(0,000)$ \\
\hline $\mathrm{Age}^{4}$ & $-5.3^{*} 10^{-6} * * *$ & $(0,000)$ & $-5.4 * 10^{-6} * * *$ & $(0,000)$ \\
\hline Child in household (dummy) & $0,320 * * *$ & $(0,034)$ & $0,130 * * *$ & $(0,030)$ \\
\hline Medium education (dummy) & 0,051 & $(0,047)$ & $0,084^{* *}$ & $(0,042)$ \\
\hline High education (dummy) & $0,214 * * *$ & $(0,049)$ & $0,109 * *$ & $(0,045)$ \\
\hline Year >= 2005 (dummy) & $-0,050^{*}$ & $(0,029)$ & $-0,0685^{* *}$ & $(0,027)$ \\
\hline Living alone (dummy) & $-0,567 * * *$ & $(0,030)$ & $-0,606 * * *$ & $(0,027)$ \\
\hline
\end{tabular}

Source: SOEP 1995-2010. Asymptotic standard errors in parentheses $* * * * * / *$ : statistically significant at the 1,5 , and $10 \%$ levels. 
Table 6: Divorce probability - parameters from a Probit estimation

\begin{tabular}{|l|cc|}
\hline & \multicolumn{2}{|c|}{ Dependent variable: divorce } \\
\hline Intercept & $-1,381^{* * *}$ & $(0,080)$ \\
\hline Age husband & $-0,010^{* * *}$ & $(0,001)$ \\
\hline Age difference husband - wife & $0,011^{* * *}$ & $(0,003)$ \\
\hline Number of children in household & $-0,015$ & $(0,013)$ \\
\hline Husband employed (dummy) & $-0,168 * * * 028)$ \\
\hline Wife employed (dummy) & 0,034 & $(0,023)$ \\
\hline Year $>=2005$ (dummy) & 0,031 & $(0,023)$ \\
\hline
\end{tabular}

Source: SOEP 1995-2010. Asymptotic standard errors in parentheses $* * * / * * *$ : statistically significant at the 1,5, and $10 \%$ levels. 
Table 7: Wage equations - parameters from an OLS regression

\begin{tabular}{|c|c|c|c|c|}
\hline \multirow[b]{3}{*}{ Intercept } & \multicolumn{4}{|c|}{ Dependent variable: natural logarithm of gross hourly wages } \\
\hline & \multicolumn{2}{|c|}{ Men } & \multicolumn{2}{|c|}{ Women } \\
\hline & $2,352 * * *$ & $(0,016)$ & $2,141 * * *$ & $(0,015)$ \\
\hline Experience (years) & $0,031 * * *$ & $(0,004)$ & $0,011^{* *}$ & $(0,005)$ \\
\hline Firm tenure (years) & $0,031 * * *$ & $(0,002)$ & $0,029 * * *$ & $(0,003)$ \\
\hline Experience $^{2}$ & $-0,002 * * *$ & $(0,000)$ & $-0,000$ & $(0,000)$ \\
\hline$(\text { Firm tenure })^{2}$ & $-0,001 * * *$ & $(0,000)$ & $-0,001 * * *$ & $(0,000)$ \\
\hline Experience $^{3}$ & $4,6 * 10^{-5 * *}$ & $(0,000)$ & $5,3^{*} 10^{-6}$ & $(0,000)$ \\
\hline (Firm tenure) $^{3}$ & $2,1 * 10^{-5 * *}$ & $(0,000)$ & $3,1 * 10^{-5} * *$ & $(0,000)$ \\
\hline Experience $^{4}$ & $-4 * 10^{-7} * *$ & $(0,000)$ & $1,1 * 10^{-7} * *$ & $(0,000)$ \\
\hline$(\text { Firm tenure })^{4}$ & $-1,9 * 10^{-7}$ & $(0,000)$ & $-3,7 * 10^{-7} *$ & $(0,000)$ \\
\hline Medium education (dummy) & $0,020 * * *$ & $(0,006)$ & $0,113 * * *$ & $(0,007)$ \\
\hline High education (dummy) & $0,384 * * *$ & $(0,006)$ & $0,399 * * *$ & $(0,007)$ \\
\hline Year >= 2005 (dummy) & $-0,012 * *$ & $(0,004)$ & $-0,0329 * * *$ & $(0,004)$ \\
\hline
\end{tabular}

Source: SOEP 1995-2010. Asymptotic standard errors in parentheses $* * * / * * / *$ : statistically significant at the 1,5 , and $10 \%$ levels. 
Table 8: Distribution of simulated household types (in \%)

\begin{tabular}{|c|c|c|c|c|c|c|}
\hline & & \multicolumn{5}{|c|}{ Number of children } \\
\hline & & 0 & 1 & 2 & $>2$ & Row sum \\
\hline \multirow{4}{*}{ 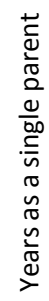 } & None & 19.6 & 12.6 & 15.7 & 9.8 & 57.6 \\
\hline & 1 to 5 Years & 0.0 & 6.2 & 8.5 & 4.8 & 19.4 \\
\hline & $>=5$ Years & 0.0 & 8.0 & 9.9 & 5.0 & 22.9 \\
\hline & Column sum & 19.6 & 26.8 & 34.1 & 19.5 & 100.0 \\
\hline
\end{tabular}

Source: Simulations with the ZEW Dynamic Microsimulation Model (ZEWDMM). Initial conditions from SOEP 2009, households with at least one individual aged 25-29. Transition probabilities estimated based on SOEP 1995-2010. 